\title{
A Conceptual Review of the Odd-Even Policy on Delhi's Urban Environment
}

\author{
Shahan Sud ${ }^{*}$ and Sindhujaa Iyengar ${ }^{\dagger}$
}

\begin{abstract}
The Odd-Even Policy is a transport rationing mechanism to control pollution levels by restricting the number of onroad vehicles per day. The aim of this policy was to reduce the number of on-road vehicles in a day by about half and thereby reducing the alarming levels of pollution in the State of Delhi. This paper identifies existing policies and evaluates how effective these policy and management options are in sustaining ecosystem services in Delhi and harmonizing them with human needs. The scope of this paper is restricted to the Odd-Even Policy implemented by the Government of Delhi in JanuaryFebruary 2016, and how structural reformations and policy adjustments can be made to the same in order to make it conducive to the indigenous ecosystem services and with that of people's needs. Consequently, this paper studies whether the proposition stands or the objectives are required to be achieved through alternatives therein. The methodology of research engages in a comparative analysis of the Odd-Even policies implemented in Beijing and Delhi. The research findings are normative, and prescribe reforms to the Delhi model. Data are obtained from secondary sources.
\end{abstract}

Keywords: Odd-Even Policy, Environmental Pollution, Ecosystem, Transport, Delhi

*Christ University, Bengaluru, India; shahansud@gmail.com

† Christ University, Bengaluru, India; sindhujaa@sindhujaaiyengar.com 


\section{Introduction}

An ecosystem is a dynamic complex of plant, animal and microorganism communities and the non-living environment interacting as a functional unit (Millennium Ecosystem Assessment, 2005). Ecosystem services are the benefits people obtain from ecosystems. These include provisioning services such as food, water, timber, and fibre; regulating services that affect climate, floods, disease, wastes, and water quality; cultural services that provide recreational, aesthetic, and spiritual benefits; and supporting services such as soil formation, photosynthesis, and nutrient cycling (Millennium Ecosystem Assessment, 2005). Hence, ecosystem services influence our security, the basic materials necessary for a good life, our health, our good social relations, and ultimately, our freedom of choice and action (Blanco \& Razzaque, 2009).

Regulatory services are those that are benefits obtained from the regulation of ecosystem processes. Ecosystems both contribute chemicals to and extract chemicals from the atmosphere, influencing many aspects of the air quality. Ecosystems influence climates both locally and globally. At the global scale, ecosystems play an important role in climate by either sequestering or emitting greenhouse gases (Millennium Ecosystem Assessment, 2005). Regulating ecosystem services appear to play a critical role in sustaining local livelihoods and providing capacity for recovery and regeneration following natural disasters or social shocks (Bennett, Peterson, \& Gordon, 2009). Cultural services are the nonmaterial benefits people obtain from ecosystems through spiritual enrichment, cognitive development, reflection, recreation and aesthetic experiences (Millennium Ecosystem Assessment, 2005). In addition to being socially and culturally important, cultural services are often economically valuable and can provide substantial contributions to material well-being (Raudsepp-Hearne, et al., 2010). Thus, "ecosystem services provide both the conditions and processes that sustain human life" (Salzman, 2006)

The degradation of ecosystem services often causes significant harm to human well-being (Millennium Ecosystem Assessment, 2005). According to a MEA report, approximately 60\% (15 out of 
24) of the ecosystem services are being degraded or being used unattainably, including the regulation of air quality. Human needs are also crucial for the effective development of citizens in our changing world. The use of cars to commute has come to become more of a necessity than a luxury. All citizens should benefit from the access, transport facilities provide in a reasonably equitable manner. This implies avoiding excessive dependence on private automobiles if certain sections of the society are not to be excluded (European Conference of Ministers of Transport).

There is as strong correlation between ecosystem services and components of human well-being. The components of human wellbeing include security, basic material for good life, health and good social relations. In specificity, there is direct relation between regulatory ecosystem services and the health component of human well-being. By health, we refer to the ability of an individual to feel well and be strong, or in other words to be adequately nourished and free from disease, to have access to adequate and clean drinking water and clean air, and to have the ability to have energy to keep warm and cool (Millennium Ecosystem Assessment, 2005).

However, human needs do impose negative externalities on the environment. A negative externality is the cost on a third party (in this case, the environment) that results from human action. If an activity has a negative externality, then its cost to the society is more than what consumers are paying for. Whether direct or indirect, human action or inaction significantly affects ecosystem services, therefore also affecting human well-being (Blanco \& Razzaque, 2009).Thus, the emerging pattern of economic growth and structure of the economy is one that is damaging to its own resource base and ultimately self-destroying (Chakraborty, 1997). Furthermore, excessive vehicular use increases greenhouse gas emission and results in air pollution that disrupts the equilibrium of the ecosystem services by affecting human well-being, specifically in terms of their access to clean air. Consequently understanding the dynamics of ecosystem services requires an integrated understanding of how changes in human desires and activities combine with ecological dynamics to produce change (Raudsepp-Hearne, et al., 2010). 
Scarcity signifies the gap between people's material desires and a society's productive potential (Panayotakis, 2011). It is the scarcity of a good, relative to effective demand, that determines its competitive market price and hence its economic value in that sense. Only things like air (in most situations) and water (in some situations) are described by the economist as a free rather than a scarce good (Bronfenbrenner, 1962). As the ecosystem services are not scarce, the marginal value of ecosystem services are zero however beneficial they may be. The marginal value is calculated in terms of the amount someone is willing to pay for the next marketable unit of a good (Sagoff, 2009). As its marginal value is zero, people tend to exhaust this scarce resource and thereby create a negative social impact on their environment.

Although people benefit from ecosystem services such as the regulation of air and water quality or the presence of an aesthetically pleasing landscape, there is no market for these services and no person has an incentive to pay to maintain the good. And when an action results in the degradation of a service that harms another individual, no mechanism exists to ensure that the individuals harmed are compensated for the damages they suffer (Millennium Ecosystem Assessment, 2005). Thus, if the act of consumption imposes costs in the form of environmental damage (Example: air pollution emitted by vehicular usage), these costs should be accounted for (Mackellar \& Jr., 1989)

This accounting for these costs is called internalising of an externality. "Internalizing externalities", to ensure that resource prices accurately reflect actual underlying social costs and benefits, is a central goal of resource and environment policy. A broad range of policy instruments- taxes, user fees, emission permits, and so onare employed to deal with externalities (Mackellar \& Jr., 1989).

Delhi's transport requirement includes provisions for both private vehicles and public transportation. The transportation system is undoubtedly the major force among the dynamic forces that influence the rate and pattern of development of the urban areas (Zimmerman, 1974). The city's high dependence on private vehicles has taken a toll on its public infrastructure and ecosystem services. Consequently, the city cannot have a sound public transportation system until it fixes the loopholes in the policies with regard to 90 
private vehicles. Hence, the State Government is required to develop for Delhi a system that acts as series of incentives that urge people to take action by consciously regulating private vehicular usage and reducing the latter's cost on society (by reducing private vehicular emissions).

Incentives are economic instruments that work through the market and alter the behaviour of economic agents (Pandey, 1998).Economic incentives is a form of governmental intervention to reduce institutional, market and policy failures. These are those instruments that affect cost and benefits of alternative action open to economic agents, with the effect of influencing behaviour in a way that is favourable to the environment (Chakraborty, 1997). They typically involve either a financial transfer between polluters and the community (example, various taxes and charges, product taxes) or the actual creation of new markets (for example marketable permits) (Organisation for Economic Co-operation and Development, 1991).

The equitable access and the sustainable management of ecosystem services largely depends on the national, legal and institutional framework (Blanco \& Razzaque, 2009). The Odd-Even Policy of the Delhi Government is one such institutional framework to control the pollution levels in the State.

Environmental Pollution is one of the serious problems in most of the mega cities of the world, especially in developing countries, which not only experiences a rapid growth of population due to increasing rate of rural urban migration but also industrialisation which is also accompanied by air, water and vehicular pollution (Nagdeve, 2004). A major source of air pollution in Delhi has been the ever-increasing number of automobiles that accounted for 63 percent of air-pollutants in 1990-91 (Tang, Prakash, \& Tang, 1998). Over the years, the intensity of the air pollution problem in Delhi is increasing. For example, the city produced 2,000 MT/Di of pollutants in 1995 as compared with an average of 1,000 MT/D about a decade ago. Ambient air quality has shown a consistent downward trend in the past decade (Government of Delhi, 1995) The WHOii Commission on Health and Environment recently concluded its work, identified air pollution as major environmental 
health problem deserving high priority for action (World Health Organisation , 1992)

On 1 1st January 2016iii, the Government of Delhi led by Chief Minister Arvind Kejriwal launched the Odd-Even model as a policy response to manage the city's changing ecosystem services. The Odd-Even model was a transport rationing mechanism to control pollution levels by restricting the number of on-road vehicles per day. Odd-numbered private four wheeler vehicles could ply on odd-numbered dates and even-numbered four wheeler vehicles on even-numbered dates. Consequently, the number of such vehicles on road in a day were to be reduced by about half.

Studies show that the pollution levels in Delhi were less than that in neighbouring regions during the Odd-Even fortnight. An assessment by the University of Chicago and the University of Harvard states that the Odd-Even programme reduced particulate air pollution concentration by $10-13$ per cent during that period (Kumar, 2016). Hence, this indicates that the model helped in the improvement of the city's ecosystem servicesiv.

However, the inability to use private transport by policy obligations (Odd-Even Policy) combined with the limited public transportation infrastructure in the city led the people of Delhi to suffer inconvenience in order to meet their basic transportation needs. This shows that changes made by this transport rationing scheme in the institutional and environmental governance framework failed to be in tandem with the human needs. A rational decision maker takes an action if and only if the marginal benefit of an action exceeds the marginal cost (Mankiw, 2012). In this context, the Odd-Even policy's marginal costs outweigh its marginal benefits as it is difficult to adjust tastes and preferences of the people in the short-run. Recognising this, Chief Minister Arvind Kejriwal on January 1st, 2016 said that it was not possible to implement the Odd-Even traffic rationing scheme on a permanent basis (Hindustan Times, 2016)v. Ergo, it is imperative for the Government of India to immediately take action to solve this policy dilemma by harmonising ecosystem services with human needs.

The effective resolution of this policy dilemma would help overcome the behavioural failure of the Odd-Even policy 
implemented by the Delhi government. The term behavioural failure reflects a parallel and familiar idea of market failurevi. A failure arises from whatever source (i.e. market, coordination, behavioural) if actions or a policy does not achieve the efficient policy baseline as defined by the rational choice theory (Shogren, 2012)

This paper identifies existing policies and evaluates how effective these policy and management options are in sustaining ecosystem services in Delhi and harmonizing them with human needs. The scope of this paper is restricted to being a conceptual review of the Odd-Even Policy implemented by the Government of Delhi in January-February 2016, and how structural reformations and policy adjustments can be made to the same in order to make it conducive to the indigenous ecosystem services and with that of people's needs.

In this context, this paper seeks to study models of the Odd-Even Policy that have worked in other places across the globe and to effectively use their key performance indicators and strengths to help enhance the marginal benefits derived from the indigenous Odd-Even policy implemented by the Government of Delhi. The amalgamation of the strengths of the similar transport rationing models to cement the Odd-Even Policy of Delhi can help resolve the Indian policy dilemma. Several cities, including Rome, Beijing, Mexico City, Bogota, Paris, Quito, La Paz and San Jose have adopted a version of the Odd-Even model. However, this paper restricts itself to the study of the Beijing case. It seeks to explore the best practices in the Beijing's Odd-Even policy that can be suitably adopted to suit the Indian context.

The research objective is to identify policy adjustments to the OddEven Model that balances ecosystem services with human needs and enhances solution sustainability. It is proposed that the objective may be achieved by making Command and Control (CAC) policies and transport policies complementary to rather than substitutes of one another. This paper studies whether the proposition stands or the objectives are required to be achieved through alternatives therein. 
Command and Control policies and transport policies are policy instruments to protect the environment from excessive pollution. These policy instruments can be divided into two categories: those that provide firms with little flexibility in achieving goals (so-called "command-and-control" approaches) and those that provide firms with greater flexibility and incentives to look for more effective ways of making sustained environmental progress (so-called market-based or incentive-based mechanisms) (Hahn \& N.Stavins, 1992). Command and Control policies constrain emission from each source and do not allow sources to trade the right to pollute (Eskeland \& Jimenez, 1992).

The development of sustainable transport policies implies reconciling environmental, social and economic objectives (European Conference of Ministers of Transport). Policies implemented at the urban level can play a crucial role in the extent to which urbanisation can translate into mobility that is less dependent in private modes while meeting growing mobility demand. This can significantly reduce negative externalities such as congestion, pollution and $\mathrm{CO}_{2}$ emissions (OECD, 2015).

The methodology of research engages comparative analysis of the Odd-Even policies implemented in Beijing and Delhi. The initial analysis is qualitative, and studies the values and limitations of the said Odd-Even policies, highlighting their efficacy or the lack thereof. The research findings are normative, and prescribe reforms to the Delhi model. Data is obtained from secondary sources.

\section{Review of Literature}

As the transport network has been predominantly road-based in Delhi, there has been a considerable growth in the road length and the motor vehicles during the period 1970 to 1991 . The growth in the number of the motor vehicles has, however, been more rapid than the growth of both road length and population (Appendix 1) (Pandey, 1998). Delhi's roads are already under terrible strain. If action is not taken immediately, that strain would become unbearable. And we would all pay a heavy price (Mishra, 2000). Therefore, transport rationing mechanisms need to be effectively deployed in a strategic and holistic manner. The Odd-Even policy 
instituted by the Government of Delhi on 1st January 2016 was a measure to reduce the number of cars on Delhi roads and thereby cutting down on pollution levels in the city.

Information on environmental characteristics can be a good guide in designing appropriate instruments for pollution control. It was noted earlier, that emission characteristics of transport vehicles depend on the technology, type of fuel, usage and the maintenance of the vehicle, operating condition, etc. However, the data on emission characteristics of motor vehicle fleet in Delhi or any other state in India is not available (Pandey, 1998). This information asymmetry is aided by the fact that emission rates of vehicle fleet in developing countries are higher owing to older vehicle fleets, using fuel of lower quality and poor enforcement of emission standards.

In this context, controlling fleet size relies on demand side interventions like ownership restrictions or taxes on vehicles, both of which directly affect the economics of using private motorized vehicles; so do incentives for lowering the average age of the vehicle fleet, whether via inspections or via higher registration fees for older cars. The impact of such fees may be regressive since poorer consumers are unlikely to able to afford new cars (Pargal \& Heil, 2000). Consequently, economists have long recognised that the command-and-control approach to pollution control, which dominates pollution policy, results in unnecessarily high costs (Lee, 1999). Furthermore, since the fleet turnover in developing countries is generally much lower than in developed countries, additional incentives to invest in new cars, fuels or technology may be warranted on social welfare grounds. To the extent that fees and fines go towards enhancing public transportation provisions, they can have an additional beneficial impact (P. \& mark, 2000).

Dense urban developments, the provision of effective public transport and strong government commitment are often the key to limiting car ownership, as shown by the experience of Singapore. Furthermore, if public mass transit systems (including bus and rail services) are well-designed and efficient, commuters can be induced to those alternatives to private vehicles if the appropriate demand management policies are adopted. There is little empirical evidence of consumers switching from car-oriented lifestyle to using public transport in the absence of strong policy interventions 
(Pargal \& Heil, 2000). Therefore, in order to fill in the gap of effective road-rationing policy that invests in an enhanced and equitable public transportation system, that is accessible to all the citizens of Delhi, makes way for this paper which crucially charts out insights to the most pragmatic solution in order to fill in the loopholes or policy dilemma of Odd-Even policy in the current urban environment of Delhi.

There is no adequate literature pertaining to the Odd-Even road rationing policy with special reference to the Delhi context. The researcher feels that it is crucial to systematically analyse the policy options that were effectively deployed in other cities where the Odd-Even policy was implemented in the past, especially Beijing (as considered in the case of this paper). This paper fills the policy void that currently exists in Delhi in order to make the indigenous Odd-Even policy, a tool to effectively reduce pollution and to initiate a public transportation system that enhances the infrastructural development of the State.

\section{Delhi's Case}

Air quality is declining in urban areas, in part because of the rapid motorization of societies world-wide. To combat the problem, various pollution control strategies have been used or proposed for urban passenger transport (Pargal \& Heil, 2000). The Odd-Even policy was implemented by the Government of Delhi to rectify the fluctuations in the relatively high pollution levels in the city caused due to enhanced vehicular pollution.

The Supreme Court has slapped a ban on the sale of high-end diesel passenger vehicles till 31 March 2016, made it mandatory for taxis to shift to CNG fuel, doubled entry tax of trucks into the city and took 10-year-old commercial vehicles powered by diesel off the city's roads (Vishwanath \& Raj, 2016). Such regulatory measures along with the existing pool of insufficient public transportation system makes this a formula that will result in an excessive burden on the existing public transport infrastructure in the city and will lead to increased sales of vehicles that are now eligible to ply on the roads of Delhi. Thus, this policy increases the consumption of the people and thereby allowing automobile giants to increase their corporate profits. Such policies of the government, rather than 
being producer oriented or dealer oriented, are targeting the consumers. Such non-technical instruments aiming at consumers, requires behavioural adaptions either in the mode of transport or necessitating periodic maintenance check to minimise pollution levels (Kathuria, 2002).

The judgment of banning certain vehicles along with the command and control measure (Odd-Even Policy) taken by Aravind Kejriwal's Government has rather ushered in action that is inverse of what the Court wanted the citizens to do. The Supreme Court judgement was taken under the knowledge of reducing the pollution levels in the city by banning the purchase of high-end diesel cars and thus leading to reduced pollution levels. In reality, the Odd-Even Policy does the opposite. In theory the policy should have halved the traffic numbers, but a host of exemptions means many more than half the nearly nine million vehicles registered in the city can still take to the roads every day (BBC, 2016). Furthermore, such command and control (CAC) policies tend to be marginally effective due to the inelastic nature of demand by the consumers. The road rationing formula of the Odd-Even policy did not impact the sale of four-wheelers during its implementation period in Delhi. The Delhi government announced the odd-even plan on December 4, 2015 and the four-wheeler sales between December $5^{\text {th }} 2015$ and January 10th 2016 totalled 8,298, compared to average sales of 7,679 vehicles in the same period over the last four years when the auto sector saw both a slump and a revival in demand (The Hindustan Times, 2016). This shows that the vehicular volume increased due to people's response to circumvent the road rationing policy by purchasing a second vehicle with an alternative number plate.

Kaustuva Barik cites research which shows that while commandand-control methods might yield dividends initially, but their gains are likely to taper off in the long run. The return of high pollution in Delhi after the Supreme Court made compressed natural gas mandatory for public transport vehicles is one such example (Kishore, 2016). In fact, any introduction of instruments say, desulphurisation or conversion of taxis from diesels to CNG might have resulted in immediate fall in emission levels, but over time with increased population of vehicles or any other factor, the 
ambient quality may have spurted back to earlier levels. Given the fact that in Delhi on average nearly 370-600 vehicles are registered daily, vii such a possibility does exist (Kathuria, 2002). And in the long run, going by a similar experiment in China, Delhi may end up having more vehicles on the road (The Hindustan Times, 2016).

\section{Beijing's Case}

Driving restrictions are used in numerous cities around the world to reduce pollution and congestion (Mahendra, 2008). In an attempt to improve the air quality of Beijing, China, before the 2008 summer Olympics, implemented a temporary road space rationing. They imposed restrictions on private vehicles by allowing even and odd license plates to drive on alternate days with the violators having to cough up 200 yuan for breaking the rules (Banerji, 2015). The restrictions, based on license plate numbers, initially prevented driving every other day and later one day per week (Viard \& Fu, 2013). On the benefits side, we find that the restrictions significantly reduce particulate matter, a pollutant estimated to claim 6.4 million life-years annually worldwide (Cohen, 2005). As a result, the traffic volume was reduced by approximately $32 \%$ during the source control period (Wang T, 2009).

Along with imposing the Odd-Even policy in Beijing, other pollution relevant policies were imposed to complement the driving restrictions. These included bus fare reduction and subway line openings (Viard \& Fu, 2013). The total utility derived by the people of Beijing amidst these restrictions was high due to an extensive and well connected public transportation system and expansion of its transit capacity. Beijing added subway capacity during the time when it imposed the Odd-Even Policy, so as to compensate the impact of people's substitution from auto to public transport.

In the short run people respond to such policy incentives by purchasing new cars. The number of vehicles in Beijing increased by $13 \%$ per year, with 4 million vehicles in 2009 (Wu, et al., 2011). However as sharing cars is difficult, purchasing a second vehicle with a different plate number to satisfy the restrictions is prohibitively expensive for most residents as is purchasing a first vehicle in response to the reduced auto congestion created by the 
restrictions (Viard \& Fu, 2013). The high cost involved in the purchase of a vehicle incentivises people reduce the consumption of cars and switch to public transportation as a regular means of transportation. Effective monitoring by traffic surveillance cameras and high penalties to prospective defaulters helped the Beijing's Odd-Even Policy to materialize on the ground level and show its desired results. As incomes in China increase, demand for driving will increase so will the number of cars (Duranton, 2011)viii. Thus, to keep auto pollution levels constant may require further increases in driving costs ( Example : Odd Even Policy). To the extent that sharing vehicles is costly, this will keep average driving costs high and reduce the equilibrium number of cars (Viard \& Fu, 2013). However, this isn't the most efficient way to reach equilibrium. A more effective allocation would result from increasing vehicle license fee or pricing congestion. Beijing has moved in this direction, beginning to limit the number of new car registrations in December 2010 (Viard \& Fu, 2013).

As a temporary measure, the Odd-even rule drastically reduced air pollution and traffic jams in Beijing. But the measure cannot be made a permanent fixture. A car is a legal private property of a citizen, and if the government bans someone from using their car on certain days of the week it will infringe upon a person's fundamental rights. Moreover, the fourth Plenum of the $18^{\text {th }}$ Central Committee of the Communist Party of China emphasised the rule of law, and no law entitles the government to permanently force half of the vehicles off the road. Therefore, Article 39 of the Road Traffic Safety Law should be applied only in temporary situations (Yang, 2014). Therefore, it is imperative to formulate long-term road rationing mechanisms that don't infringe on the rights of the individuals and also make mobility efficient by widespread public transit connectivity.

Furthermore, strategies for reducing PAHix emissions from vehicles in Chinese megacities, and associated inhalation cancer risk, include the development and encouragement of public transportation and more stringent vehicle emission standards $(\mathrm{Wu}$, et al., 2011). 


\section{Comparative Review of Delhi's and Beijing's Case}

Although CAC measures like the Odd-Even Policy was initiated and enacted in both Delhi and Beijing, their impact differed as they were implemented differently. Taking the case of Beijing, along with imposing the Odd-Even policy, other pollution relevant policies were imposed to complement the driving restrictions. These included bus fare reduction and subway line openings (Viard \& Fu, 2013). Therefore, the general public were incentivized to use public transport. Furthermore, Beijing added subway capacity during the time when it imposed the Odd-Even Policy, so as to compensate the impact of people's substitution from auto to public transport.

On the other hand, when the Odd-Even Policy was implemented in Delhi, it was done so in the isolation of other such policy incentives that made public transportation a cheaper and a more economically convenient way to travel. Rather than making public transportation system reliable and attractive enough to encourage the car users to shift to public transport, surge pricing by cab aggregators like Ola and Uber, made transportation more costly than before. Furthermore, the capacity of the Delhi metro remained the same and the excessive commuters added to the strain of the limited public infrastructure.

On the air quality front, the Delhi's Odd-Even scheme has provided limited benefits. This can be attributed to the fact that the share of private cars is small in the production of PM2.5 levels in Delhi (source apportionment study, IIT-K), and consequently, only marginal reductions could be achieved through the Odd-Even scheme. In winters, the Odd-Even experiment led to a $\sim 7 \%$ reduction in the 24-hour PM2.5 concentrations; however, in summers, when the pollution levels are relatively lower and the share of vehicular sources is lower too, the impact of the scheme is further reduced (The Energy and Resources Institute, 2016).

In summation, it can be sought that even the second phase of OddEven Policy couldn't successfully limit the level of pollution in the state of Delhi. This can be inferred from the fact that the air pollution levels in Delhi rose by 23 percent during the second phase of the odd-even registration rule, from April 15 to April 29, 
over the previous 14 days (April 1 to April 14), based on an analysis of PM (particulate matter) 2.5 data (Business Standard, 2016).

\section{Policy Formulation}

For India, the outcomes of the urban scenarios through modal shares show very contrasting trend for different scenariosx. In the baseline scenarioxi, the modal share of private cars increases from $32 \%$ in 2010 to $59 \%$ in 2050, to the detriment of the public transport (from $42 \%$ to $22 \%$ ) (Appendix 2). This shows that the natural evolution of mobility pattern in urban India is towards private mobility (OECD, 2015). This trend forecast brings forward, in the context of Delhi, the importance of transport regulation mechanisms, transport policies and an effective policy implication with an enhanced technological capability and reach.

The limitation of this research is that we tend to look at how to combat the increasing $\mathrm{CO}_{2}$ levels in Delhi without sufficiently tackling the problem of congestion. Furthermore, another limitation of this research is that most policy solutions offered as response to combat the high pollution levels caused due to the Odd-Even policy tend to be socialistic in nature as this topic is subsumed under the broader category of sustainable development and growth.

Government agencies responsible for enforcing environmental laws can justify larger budgets under a command-and-control approach because it requires more detailed involvement in pollution control decisionsxii. That the larger benefits from the incentive approach would spread those benefits over everyone in the general public does nothing to offset the political advantage of the command-and-control approachxiii (Lee, 1999).

"U.S. environmental policies, which are primarily of the command and control method, move society onto a higher marginal abatement cost curve than is necessary...Because of the high abatement costs, it is likely that the target level of pollution that is chosen will be greater than the optimal level of pollution" (Kahn, 1995). Consequently, the efficient level of pollution would be less with a policy of economic incentives than with higher marginal abatement costs of the command-and-control approach (Lee, 1999). In India, so far there has been an overwhelming reliance on CAC 
measures (Pandey, 1998). The Odd-Even policy is one such command-and-control measure whose implementation in Delhi has led to an increase in the marginal cost of abatement.

The Odd-Even Policy is an initiative by the Government of Delhi whose unintended consequences outweighs its intended consequences. According to the principles of economics all human beings are said to be rational individuals and they seem to respond to incentives. The incentive of the Odd-Even policy can lead to unintended consequences that may rather lead to the disutility of policy framework and increased consumption expenditure by the public. If instruments require scrapping of old vehicles, simply mandating sales of new clean vehicles does not fully address the ambient air quality problem. This is because it still remains unknown on who will purchase the vehicles, where they will be living (whether highly polluted or cleaner regions), or how much will they drive the vehicles once purchased (Kathuria, 2002). Hence, the effective policy formulation of the Odd Even Policy by the Government of Delhi tends to backfire on its expected results as it creates a negative obligation for the citizens and also encourages them to purchase a second vehicle with an alternative number to help them circumvent the rule, thereby promoting sales of the automobile firms.

Free market forces is the key guiding factor that brings the supply and demand for goods and services into a state of equilibrium. The use of policy incentives (command-and-control measure), like the Odd-Even policy thus increase the marginal cost of abetment and reduce the optimum utilisation of resources. Such a policy gives the citizens of Delhi an incentive to purchase an additional car so that they don't face the disutility of deriving only partial satisfaction from their first car due to the government's Odd- Even Policy. This is effectively shown in Model 1. 


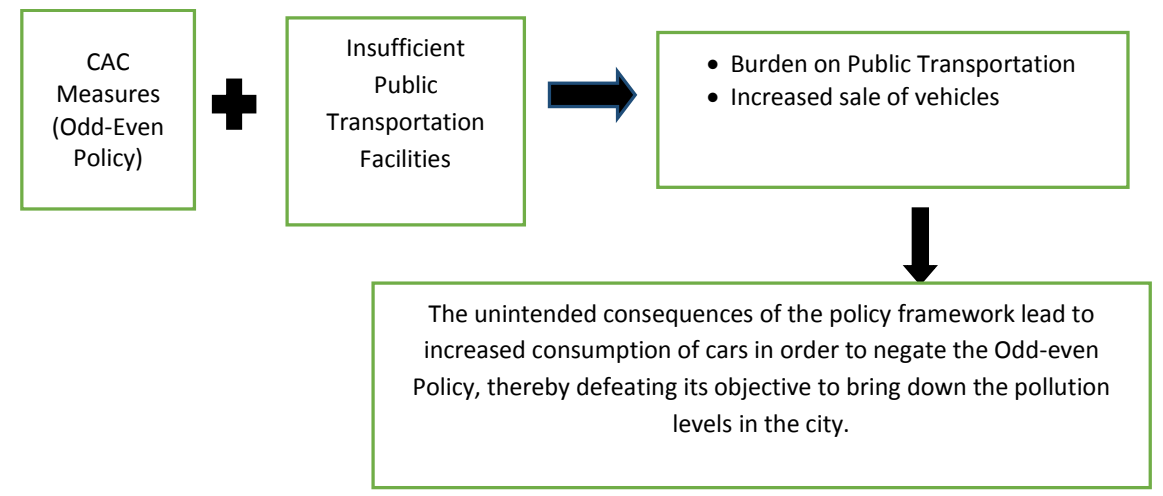

This unintended nature of the Odd-Even policy dilutes its intended purpose. As incentives alter the decision making capability of an individual, any policy that increases the cost of maintaining a car decreases its utility and reduces satisfaction among the people.

Market based policies can help us to solve this policy dilemma of how to enhance our utility and efficiency and at the same time control the levels of air pollution. Market based policies will not only be cost-effective (in a static sense), but will also provide dynamic incentives for the development and adoption of improved pollution controlled technologies (Hahn \& N.Stavins, 1992). Market-based incentives generally require the regulator to estimate only aggregate (rather than individual) costs of abatement to minimise costs. A regulator would, for instance, issue enough tradable permits for the marginal benefits and costs of abatement to be equated overall; a polluter whose abatement costs are high would purchase permits, whereas one with cheaper abatement options would prefer to reduce emissions. A pollution tax can also achieve cost effective abatement. It allows each polluting source to decide whether to pay the tax or to undertake additional abatement, with the result that low-cost abatement is selected since each source will abate only if the marginal costs of abatement do not exceed the tax rate (Eskeland \& Jimenez, 1992).

In developing countries, where the tax base is often narrow and rates high, distortionary costsxiv are likely to be higher (World Bank, 1991). Furthermore, the pollution taxes can raise revenue 
while improving efficiency, by persuading firms and households to reduce negative externalities. Taxing commodities with negative externalities will thus reduce not only the efficiency losses arising from the externality itself (say, damage from pollution) but also the efficiency losses related to generating revenue, since the proceeds may allow other rates to be reduced (Eskeland \& Jimenez, 1992). In this context, economic incentives like higher tax on the second car per family and initiation of congestion tax can considerably change the consumption patterns of most families in Delhi by increasing their costs. The heart of the public transportation problem is financial (Zimmerman, 1974). Barik argues that using economic incentives, such as a congestion tax, would yield double dividends in terms of reducing traffic as well as generating additional revenue, which could be used to augment public transport. A tax of Rs 1000 per month on cars and Rs 500 per month on two-wheelers (taking into account just vehicles registered in Delhi) can generate a tax of more than Rs 6,700 crore, according to Barik's calculations. Such funds can be used to revamp the city's public transport infrastructure, and ensure last-mile connectivity for daily commuters, reducing the demand for cars in the city (Kishore, 2016). In most developing countries, input taxes to curtail emissions would be easier to implement than a completely new scheme such as permit trading (Eskeland \& Jimenez, 1992). Furthermore, if people behave as if they are "addicted to" the good generating the negative environmental impact an optimum environmental tax should exceed the standard Pigouvian Taxxv. Analogously, encouraging less-environmentally damaging substitute behaviour might be achieved through policies that incorporate mechanisms which provide incentives to precommitxvi (Shogren, 2012)

The Odd-Even Policy has resulted in lacklustre improvements in the pollution levels of Delhi. The search for new instruments should recognize that appropriate mechanisms will vary depending on the relevant government agency's resources and capabilities (Hahn \& N.Stavins, 1992).

We have formulated a model that will assist the policymakers to overcome the policy dilemma and make the Odd-Even Policy a bulletproof formula. We propose a model where command and 
control policies like (Odd-Even policies) are accompanied by a reduction in public transportation fares, thereby making public transit convenient and allowing more people to use it and a strict implementation of transport policies. These transport policies will include initiating cordon/congestion pricing, reworking on parking policies, putting a ceiling on the number of cars registered in Delhi (initiating carrying capacity), making the pollution charges regulation stricter, implementing stricter vigilance facilities and creating pedestrian zones. As the CAC policies make using cars more costly, a simultaneous reduction in the fares of public transportation helps peoples people change their preferences with change in prices and expectations. Dense urban developments, the provision of efficient public transport and strong government commitment are often the key to limiting car ownership, as shown by the experience of Singapore (Pargal \& Heil, 2000).

Our model uses transport policies as exogenous variables that play a crucial role in influencing the means of transportation that people take. To some extent congestion is a form of rationing that reflects the absence of pricing mechanism for road space. In some places chronic congestion is the result of under-investment in road capacity over a prolonged period. Frequently, it results from a failure to integrate land-use and transport planning (European Conference of Ministers of Transport). The national capital Delhi is a case in point. To eradicate the problem of congestion we need policies that improve traffic flows and increase average speed. These can be achieved by a set of policies; a.) Direct action to reduce the number of the vehicles on the road via quotas, restrictions on ownership and road pricing or congestion pricing; b.) Efficiency enhancement, through changes in road infrastructure (Bus lanes, synchronization of traffic, etc.); c.)By increasing the supply of roads (Pargal \& Heil, 2000). In an urban centre like Delhi, "options b" and "option c" will not be viable as Delhi has exhausted all its land and there is no further scope of expansion within the city. However, the first option of road or congestion pricing can effectively be employed in densely vehicular populated region like Delhi. Congestion pricing means that private automobiles entering central business districts (CBDs) like Connaught Place, Nehru Place, ITO, etc. will have to pay a charge (Mishra, 2000). If this policy initiative was to be used singly then it 
wouldn't create as much impact as it would have made if it was executed along with CAC measures and reduced public transportation fares. In this policy solution, the congestion can be seen as disincentive for people and the only benefit that the people will get is a slight reduction of the vehicular population on the roads. Therefore, the cost of congestion outweighs the slight reduction of vehicular traffic in certain traffic districts.

Regulatory measures need to be restructured to act as instruments of internalisation of the high cost of vehicular pollution. The shortrun impacts could be minimised by gradual introduction and setup to optimal rates allowing time for adjustment (Chakraborty, 1997).The parking policy of Delhi can be reworked by hiking the parking charges in CBDs and institutional areas to discourage private automobiles. Furthermore, the parking rates should be levied on an hourly basis rather than being levied at flat rates. This will increase the maintenance cost of private vehicle and thereby making its marginal cost more than its marginal benefit. The other aspect of parking policy would entail higher charges for on-street parking than off-street parking. This requires the government to make much more by way of parking facilities than is available at present. This would go a long way in removing the haphazard parking on the roads, which contributes immensely to congestion (Mishra, 2000). However, the creation of additional parking facilities will not be viable as Delhi has exhausted all its land and there is no further scope of expansion within the State.

Pollution charges may yield more or less the than what is needed for environmental expenditures, so the benefits of earmarking should be examined in the broader context public expenditure analysis (McCleary, 1991). On similar lines, an environment compensation charge of Rs 1,300 on heavy commercial vehicles and Rs 700 on light trucks, which enter the Capital were levied, starting from October $7^{\text {th }} 2015$ (Nair, 2015). This, however, only makes people to pay for the pollution that they generating, it doesn't really reduce the vehicular emissions. In practice, monitoring damages or even emissions at the source may be costly, particularly in developing countries, for technological and institutional reasons (Eskeland \& Jimenez, 1992). 
We propose initiating a mechanism of carrying capacity which restricts the number of private vehicles that are registered in Delhi. This ceiling will help in bringing down the number of cars by way of government decree. However, by restricting the number of cars that come on the roads every year, is a policy, acts as a catalyst for allowing bribes and under-the-table transactions to facilitate more licence permits than the ceiling amount.

Furthermore, we propose the creation of pedestrian zones where only citizens can walk to commute and no such vehicle should be permitted within the vicinity of these zones. Areas in the Delhi that can be converted into pedestrian zones include Lajpat Nagar, Chandni Chowk and Connaught Place Inner Circle. However, the practicality of this can be questioned as it will lead to urban planning problems in a highly populated city like Delhi.

In order for the above mentioned transport policies to function in communion with the CAC policies like Odd-Even policy in Delhi vigilance is of prime importance. Therefore, to ensure the proper implementation of these transport and command-and-control policies in Delhi, increased installation of CCTV cameras across the roads and CBDs of Delhi is necessary.

In addition to these market incentives and fiscal policy measures, we propose a model whereby the Adhaar card be linked to the purchase of fuel of each citizen of Delhi. With the Adhaar card being given a statutory status under the auspices of the Union Budget 2016-17, the Adhaar card can now be used to assess and record the fuel purchases of each individual and also restrict excessive use by putting a ceiling on the amount of fuel each individual can consume in a month. If people consume more than the compliance amount then a surcharge would be waived on each litre of fuel that may consume. As fuel and cars are complementary goods, the regulated usage of the former can lead to more prudent use of vehicles. Such form of indirect tax, if initiated, can help control the problem of air pollution in the long run.

Economic growth and environmental balance do not go hand in hand. Rather, they oppose each other. Higher economic growth requires natural resources to be exploited. Environmental balance can only be obtained if there is less or no pollution. For a 
developing country like India to completely stop polluting is something that is too utopian to be true. However, what we can do is that can do is go for a sustainable growth model whereby our societal costs are at the minimum. We propose a model where command and control policies like (Odd-Even policies) are accompanied by a reduction in public transportation fares, thereby making public transit convenient and allowing more people to use it and a strict implementation of transport policies.

Furthermore, we can reach equitable growth and development by shifting to cleaner technologies. The transitioning of our transportation sector from its near sole dependence on oil to electricity can lead to big reductions in carbon pollution along with improvements in air quality (NRDC, 2015). The Government of Delhi can incentivize the production of Plug-in Electric Vehicles (PEV) by giving them tax breaks and easier regulatory clearances. This ease in the production process will help in reducing the costs of the electric cars in India and consequently help in bring down the costs of PEV as compared to fuel run vehicles. This will encourage consumers to purchase cars with cleaner technologies and lesser externalities, at the cost of a normal car. This policy initiative of the government will not only help to boost the industry of electric cars but it will also help to cut down the ambient pollution levels in the city.

The road- rationing policy mechanism in Delhi has taken a chaotic start. In order for this chaotic start to conclude logically and efficiently, long-term strategies are crucial to harmonise eco-system services with human needs.

While the number of deaths from outdoor air pollution fell by $4 \%$ in OECD countries between 2005 and 2010, partly due to stricter vehicular emission controls China and India have seen increases of $5 \%$ and $12 \%$, respectively. Health impact costs of outdoor air pollution in China and India in 2010 were estimated at USD 1.4 trillion and 0.5 trillion, respectively (OECD, 2015). Although increased vehicle activity typically degrades air quality, stringent vehicle emissions and fuel standards in place in many developed countries have decoupled the relationship between vehicle activity and emissions since most advanced emission controls can effectively eliminate over 90 percent of the local air pollutants from 108 
engines (Chambliss, S. et al., 2013) The leapfrogging, by the Ministry of Road Transport \& Highways, from BS-IVxvii to BS-VI emission norms directly by April 1 1 st 2020 would act as a productive measure to reduce vehicular pollution in India in the long-run (HT Media, 2016).

This paper shows that an integrated policy aiming at climate and health objectives work best, and it is possible to achieve substantial climate change mitigation, less reliance on private car and lower health impacts by promoting low sprawl and road development, and higher rates of public transit alongside more stringent controls for vehicle emissions. More specifically, results also show that for all regions analysed, increasing the share of public transport in urban mobility will only bring significant health benefits if coupled with regulations that assure improvement in emission control technologies for buses (OECD, 2015). The most efficient approach to achieving sustainable development of the transport sector requires a combination of regulatory instruments and restructuring of charges and taxes on the basis of marginal costs to provide incentives to reduce external costs to optimum levels (European Conference of Ministers of Transport). Ergo, a mix of CAC policies along with reduced public transportation costs and effective implementation of transport policies can help to bring down the pollution levels in Delhi in the short-run (This is effectively shown in Model 2). By coaxing people out of their cars and with increase of safer and convenient public transit ridership, cities can reduce emissions and air pollution and enjoy safer and more liveable urban environments, with less time wasted in congestion (Gupta, 2016). The long-term strategies to harmonise ecosystem services with human needs will be possible in the next five years' time as Delhi would be technologically equipped to carry out a plan that is proposed by us. 


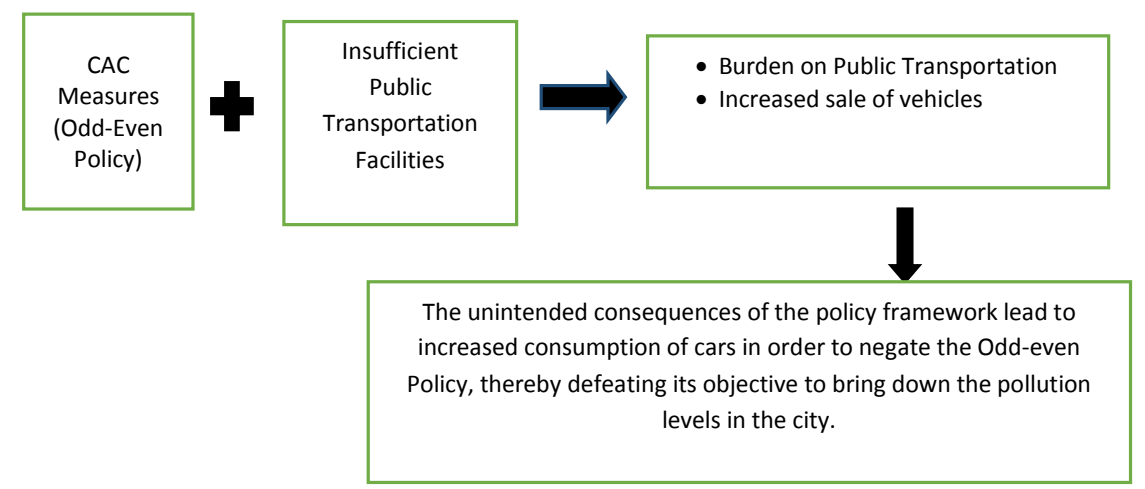

\section{References}

Ackerman, B., \& Hassler, W. (1981). Clean air/dirty air, or how the Clean Air Act became a multibillion dollar bailout to high-sulfur coal producers and what should be done about it. New Haven: Yale University Press .

Banerji, R. (2015). 5 Cities Implemented The \#EvenOdd Road Rationing Policy. But Was It Effective? New Delhi : indiatimes.

BBC. (2016). Delhi 'odd-even' car policy fails to curb pollution. New Delhi.

Becker, G. (1983). A theory of competition among pressure groups for political influence. Quarterly Journal of Economics, pp. 371-400.

Bennett, E., Peterson, G., \& Gordon, L. (2009). Understanding relationships among multiple ecosystem services. Ecology Letters 12, 1394-1404.

Blanco, E., \& Razzaque, J. (2009, August). Ecosystem Services and Human Well-Being in a Globalized World: Assessing the Role of Law. human Rights Quarterly, Vol. 31, No. 3, pp. 692-720.

Bronfenbrenner, M. (1962, July). The Scarcity Hypothesis in Modern Economics . American Journal of Economics and Sociology, Vol. 20, No. 3, pp. 265-270.

Buchanan, J., \& Tullock, G. (1975). Polluters profits and political response;Direct controls versus taxes. The American Economic Review, pp. 139-147.

Business Standard. (2016, April 30). Delhi's air pollution rises 23\% during second odd-even phase. New Delhi.

Chakraborty, M. (1997, May 17-30). Economic Incentives for Biodiversity: Will They work in Developing Countries? Economic and Political Weekly, Vol. 32, No. 20/21, pp. 1071-1073. 
Chambliss, S. et al. (2013). the impact of Stringent Fuel and Vehicle Standards on Premature Mortality and Emissions. The International Council on Clean Transportation .

Cohen. (2005). The Global Burden of Disease due to Outdoor Pollution. Journal of Toxilogy and Environment Health, Part A, 68, pp. 1-7.

Cremer, H., \& Ladoux, F. G. (2001, October). Second-Best Pollution Taxes and the Structure of Preferences. Southern Economic Journal, Vol. 68, No. 2, pp. 258-280.

Delhi Statistical Handbook. (1993). Government of Delhi.

Dubowsky, S., Wallace, L., \& Buckley, T. (1999, July-August). The contribution of traffic to indoor concentrations of polycyclic aromatic hydrocarbons. Journal of Exposure Analysis and Environmental Epidemiology, pp. 312-321.

Duranton, G. a. (2011). The Fundamental Law of Road Congestion: Evidence from US cities. American Economic Review,58, pp. 818-845.

Eskeland, G. S., \& Jimenez, E. (1992, July). Policy Instruments for Pollution Control in Developing Countries. The World Bank Research Observer, Vol. 7, No. 2, pp. 145-169.

European Conference of Ministers of Transport. (n.d.). Sustainable Transport Policies. Organisation for Economic Co-operation and Development (OECD).

Government of Delhi. (1995). Delhi Environmental Status Report. New Delhi.

Gupta, D. S. (2016). CSIR-CRRI study show ways on odd even policy in Delhipublished by . New Delhi: CSIR-Central Road Research Institute.

Hahn, R. W., \& N.Stavins, R. (1992, May). Economic Incentives for Environmental Protection: Integrating Theory and Practice. The American Economic Review, Vol. 82, No. 2, Papers and Proceedings of the Hundred and Fourth Meeting of the American Economic Association, pp. 464-468.

HT Media. (2016). Odd-Even: Govt shift on BS norms, HC questions whether xar rationing can end by Jan 8 . New Delhi: HT Media.

John, C. (n.d.). The Distortionary Costs of Taxation. The University of Melbourne .

Kahn, J. (1995). The economic approah to enironmental and natural resources. San Diego: Harcourt Brace College Publishing.

Kathuria, V. (2002, March 23-29). Vehicular Pollution Control in Delhi: Need for Integrated Approach. Economic and Political Weekly Vol. 37, No. 12 , pp. 1147- 1155.

Lee, D. R. (1999, July ). Lowering the Cost of Pollution Control versus Controlling Pollution. Public Choice, Vol. 100, No. 1/2 , pp. 123-134.

Mackellar, F. L., \& Jr., D. R. (1989, October). Measuring Natural Resource Scarcity . Social Indicator Research, Vol. 21, No. 5, pp. 517-530. 
Mahendra, A. (2008). Vehicle Restrictions in Four latin American Cities: Is Congestion Pricing Possible ? Transport Review,28, 105-133.

Maloney, M., \& McCormick, R. (1982). A positive theory of environmental quality regulation. The Journal of Law and Economics , pp. 99-123.

McCleary, W. (1991). The Earmarking of Government Revenue: A Review of Some World Bank Experience. World Bank Research Observor, Vol. 6, No. 1, pp. 81-104.

McCurdy, R. O. (1999). The Failure of Market Failure . Journal of Policy Analysis and Management, Vol. 18, No. 4, pp. 558-578.

Millennium Ecosystem Assessment. (2005). Ecosystems and Human WellBeing: Synthesis. Washington D.C. : Island Press.

Mishra, S. (2000, June 10-16). Forestalling Transport Chaos in Delhi. Economic and Political Weekly Vol. 35, No. 24 , pp. 2061-2065.

(1991-93). Motor Transport Stastistics of India. New Delhi: Ministry of Surface Transport '.

Nagdeve, D. A. (2004, May). Environmental Pollution and Control: A Case Study of Delhi Mega City. Population and Environment, Vol. 2, No. 5, pp. 461-473.

Nair, H. V. (2015). SC imposes pollution cess of Rs 700 and Rs 1300 on trucks entering Delhi. New Delhi: Mail Today.

Nikolaou, K., Masclet, P., \& Mouvier, G. (1984, January 13). Sources and chemical-reactivity of polynuclear aromatic hydrocarbons in the atmosphere - a critical-review. Science of The Total Environment, pp. 103-132.

OECD. (2014). ITF Transport Outlook . Retrieved from http:/ / dx.doi.org/10.1787/888933169004

OECD. (2015). ITF Transport Outlook 2015. Organisation for Economic Cooperation and Development .

Organisation for Economic Co-operation and Development . (1975). The Polluter Pays Principle . Paris: OECD .

Organisation for Economic Co-operation and Development. (1991). Environmental Policy: How to Apply Economic Instruments . Paris: OECD.

P., S., \& mark, H. (2000, September). Reducing air pollution from urban passenger transport; A framework for policy analysis. Journal of Environmental Planning and Management, p. 665.

Pandey, R. (1998, November 7-13). Fiscal Options for Vehicular Pollution Control in Delhi. Economic and Political Weekly, pp. 2873-2880.

Pargal, S., \& Heil, M. (2000, September). Reducing air pollution from urban passenger transport: A framework for policy analysis. Journal of Environmental Planning and Management, p. 665.

Parshigian, P. (1984). The effects of environmental regulation on optimal plant size and factor shares. The Journal of Law and Economics, pp. 1-28. 
Raudsepp-Hearne, C., Peterson, G. D., Tengo, M., Bennett, E. M., Holland, T., Benessaiah, K., \& Pfeifer, G. K. (2010, September). Untangling the Environmentalist's Paradox: Why Is Human Well-being Invreasing as Ecosystem Services Degrade? . Oxford university Press, pp. 576-589.

Salzman, J. E. (2006). A Field of Green: The Past and Future of Ecosystem Services.

Shogren, J. (2012). Behavioural Economics and Environmental Incentives. OECD Environment Working Paper,No. 49. OECD Publishing.

Tang, S.-Y., Prakash, V., \& Tang, C.-C. T.-Y. (1998, September-December ).

Local Enforcement of Pollution Control in Developing Countries: A Comparison of Guangzhou, Delhi and Taipei. Journal of Public Policy, Vol. 18, No. 3 , pp. 265-282.

The Economist. (1991). Willia Reilly's green precision weapons. The Economist.

The Energy and Resources Institute. (2016). Analysis of Odd-Even scheme phase-II. New Delhi: TERI.

The Hindustan Times . (2016). Road-Rationing alone may not help. New Delhi: ProQuest .

Tonne, C. C., Whyatt, R. M., Camann, D. E., Perera, F. P., \& Kinney, a. P. (2004, May). Predictors of personal polycyclic aromatic hydrocarbon exposures among pregnant minority women in New York City. Environmental Health Perspective, pp. 754-759.

Vardhini, P. (2016). All you wanted to know about BS VI emission norms. Business Line.

Viard, V. B., \& Fu, S. (2013). The Effect of Beijing's Driving Restrictions on Pollution and Economic Activity. Beijing.

Vishwanath, A., \& Raj, A. (2016). Supreme Court bans luxury diesel vehicle sales in Delhi till 31 March. New Delhi : LiveMint.

Wang T, X. (2009). Assessment of traffic-related air pollutioon in the urban streets before and during the 2008 Beijing Olympics trafic control period. Environmental Science Technology, Vol. 44, No. 35.

(n.d.). White Paper on Air Pollution in Delhi. Government of India.

World Bank . (1991). Lessons of Tax Reforms . Washington, D.C. : World Bank .

World Health Organisation . (1992). Our Planet Our Health: Report of the WHO Commission on Health and Environment. Geneva: WHO.

Wu, Y., R, W., Y, Z., B, L., L, F., K, H., \& al., e. (2011). On-road vehicle emission control in Beijing: past, present, and future. Environmental Science Technology, Vol. 45, No. 1, pp. 147-153.

Yang, H. (2014). Road space rationing is not the answer. New York: China Daily. 
Zimmerman, J. F. (1974). Public Transportation. Proceedings of the Academy of Political Science, Vol. 31, No. 3 (pp. 214-224). New York: Academy of Political Science.

\section{Appendix 1}

\begin{tabular}{|c|c|c|c|c|}
\hline Year & $\begin{array}{c}\text { Population } \\
\text { ( Lakh) }\end{array}$ & $\begin{array}{c}\text { No. of Motor } \\
\text { Vehicles Registered } \\
\text { (Lakh) }\end{array}$ & $\begin{array}{c}\text { Road Length } \\
\text { ( Kms) }\end{array}$ & $\begin{array}{c}\text { Vehicle } \\
\text { Density } \\
\text { (No/km) }\end{array}$ \\
\hline $1970-71$ & 40.66 & 2.04 & 8231 & 24.78 \\
\hline $1980-81$ & 62.20 & 536 & 14316 & 37.44 \\
\hline $1990-91$ & 93.70 & 18.13 & 21564 & 84.08 \\
\hline 1995-96 & 26.29 & & \\
\hline Growth Rates (Per cent) & 10.14 & 5.69 & \\
\hline 1971-1981 & 4.34 & 12.96 & 4.18 & \\
\hline $1981-1991$ & 4.18 & 1154 & 4.93 & \\
\hline $1971-1991$ & 4.26 & &
\end{tabular}

Source: (Delhi Statistical Handbook, 1993); (Motor Transport Statistics of India, 1991-93) and (White Paper on Air Pollution in Delhi)

\section{Appendix 2}

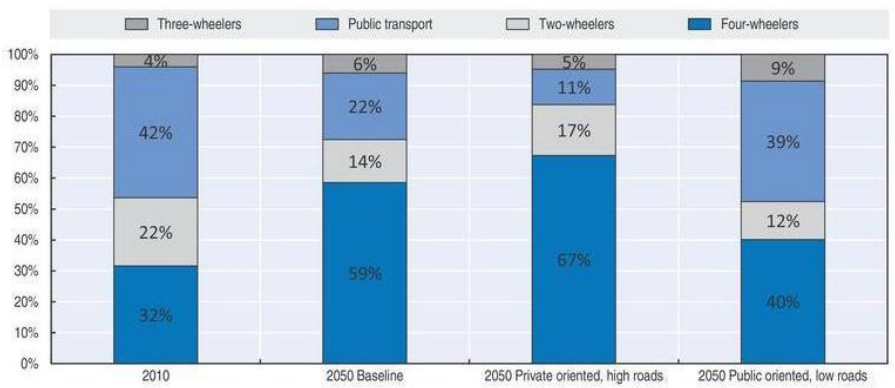

Figure 1 Model shares under different policy scenarios in Indian cities. 2010 and 2050 Passanger-kilometers

Statistics source: $(O E C D, 2014)$

\section{End Notes}

\section{i MT/d: Metric tonnes per day}

ii World Health Organisation

iii The Odd-Even Policy was implemented in Delhi for a period of 15 days (From $1^{\text {st }}$ January $2016-15^{\text {th }}$ January 2016).

iv It may be noted that the data available on the National Air Quality Index website did not show any change in the pollution levels in the 
week when the Odd-Even policy was being tested. In fact, petitioner Gunjan Khanna stated, "There is no reasonable nexus between this policy and the objective of curbing pollution" (Mathur, 2016); The Delhi government in its press statement claimed that air pollution levels continued to decline until 12 ${ }^{\text {th }}$ January 2016 (The Times of India, 2016).

v Arvind Kejriwal stated that these were just weapons that are used on a temporary basis to curb dangerous levels of pollution (Hindustan Times, 2016).

vi Market failure is a circumstance where the pursuit of private interest does not lead to an efficient use of society's resources or a fair distribution of society's goods (McCurdy, 1999)

vii A report says that in 1999, 370 vehicles were registered every day. (Source: The Hindustan Times, October, 1, 2000). Another report says that on average 600 vehicles are registered every day in Delhi (Source: http:// www.htpcindia.com/lpgfuel.html).

viii Duranton and Turner (2009) provide empirical evidence that a fundamental law of auto congestion holds, in which a natural level of congestion is reached in the long run which equates driving demand and average cost of commuting as determined by road capacity

ix PAHs are widespread environmental pollutants that are formed in the combustion process of carbonaceous materials at high temperature (Nikolaou, Masclet, \& Mouvier, 1984). Emissions from traffic have been found to be the main outdoor source for the indoor PAH concentration at urban and suburban locations in many industrialized countries (Dubowsky, Wallace, \& Buckley, 1999). Motor vehicle emissions account for around $46-90 \%$ of the mass of individual PAHs in ambient air particles in urban areas (Tonne, Whyatt, Camann, Perera, \& Kinney, 2004).

$x$ These scenarios imply land-use scenarios. Land use scenarios refer again to different evolutions of urban density. Urban density plays a role in infrastructure development through its impact on road provisions (OECD, 2015)

$x i$ In the Baseline scenario, the coefficients are computed using all cities from each city category. In this scenario, the average urban density in Indian cities is 30\% higher in 2050 than in 2010.

xii As observed in The Economist (1991:28),"The EPA exists to regulate things, not to see the market do the job for it." (The Economist, 1991)

xiii Becker $(1983,1985)$ develops a model of political competition in which more efficient policies have an advantage over less efficient ones. But Becker's model doesn't consider the distortions caused by differences 
in the political influence of groups with opposing interests. (Becker, 1983)

xiv The 'excess burden', or distortionary cost, of a tax is thus the extent to which the total money measure of the welfare loss from the tax exceeds the tax paid (John).

xv Since A.C. Pigou's (1920) seminal contributions, the expression "Pigouvian taxes" has been used for taxes intended to discourage activities with negative externalities. The "polluter pays" principle, as defined by the OECD guidelines (Organisation for Economic Cooperation and Development, 1975) is not a "true" Pigouvian instrument, because it usually requires payment for abatement but not for damages from emissions. The Pigouvian prescription for correcting an externality is to levy a tax equal to its marginal social damage (Cremer \& Ladoux, 2001).

xvi Less environmentally damaging behaviour includes commuting via public transport or cycling. In policy terms this might include a stream of benefits such as subsidies (Pargal \& Heil, 2000) which are dependent on habitual use (Shogren, 2012)

xvii Introduced in the year 2000, the Bharat norms are emission control standards put in place by the government to keep a check on air pollution. Based on the European regulations (Euro norms), these standards set specifications/limits for the release of air pollutants from equipment using internal combustion engines, including vehicles. Typically, the higher the stage, the more stringent the norms. The BS IV norms were introduced in 13 cities apart from the National Capital Region from April 2010. Currently, BS IV fuel is being made available across the country in stages, with the entire nation expected to be covered by April 1 ${ }^{\text {st }} 2017$ (Vardhini, 2016). 